\title{
SEMIÓTICA DIGITAL EN LASERIE DE FICCIÓN EL MINISTERIO DEL TIEMPO
}

DIGITAL SEMIOTICS IN FICTION SERIES EL MINISTERIO DEL TIEMPO

\author{
Inmaculada BERLANGA FERNÁNDEZ \\ Universidad Internacional de la Rioja (UNIR) \\ inmaculada.berlanga@unir.net
}

\author{
José Borja ARJONA MARTÍN \\ Universidad de Granada \\ jbarjona@ugr.es
}

\begin{abstract}
Adoración MERINO ARRIBAS
Universidad Internacional de la Rioja (UNIR) dory.merino@unir.net
\end{abstract}

Resumen: El artículo estudia la serie de ficción española El Ministerio del Tiempo como ejemplo de fenómeno narrativo diferente, sociocultural y colaborativo que explota las diferentes formas de transtextualidad gracias a la tecnología. Se emplea una metodología inductiva sobre la expansión transmedia de los relatos televisivos y un análisis del mundo narrativo

1. Investigación financiada parcialmente por UNIRresearch en su Plan propio de Investigación 2015-2017. Grupo de investigación Procomm (Prospectivas en la Comunicación Multimedia). 
transmedia de la serie desde una perspectiva semiótico-comunicacional. Se completa con una entrevista en profundidad a Javier Olivares, su creador y guionista. A su vez destaca una original forma de emplear la intertextualidad. Estos parámetros pueden ser considerados las claves del éxito social y mediático de esta ficción.

Palabras clave: Transmedia. Transtextualidad. Teleseries. Semiótica. Redes sociales. El Ministerio del Tiempo.

Abstract: The present paper aims to study the TV series El Ministerio del Tiempo as an example of a different socio-cultural and collaborative narrative phenomenon that exploits the different forms of transtextuality due to technology. An inductive methodology based on transmedia expansion of television stories and an analysis of transmedia narrative world of the series is used from a communicational-semiotics perspective. The research is completed by an in-depth interview to Javier Olivares, creator and writer of this fiction. At the same time, it highlights an original way of using hypertextuality. These parameters can be considered the key to the success of this fiction.

Key Words: Transmedia. transtextuality. TV series. Semiotics. Social networks. El Ministerio del Tiempo.

\section{INTRODUCCIÓN Y ESTADO DE LA CUESTIÓN}

Las series de ficción españolas se encuentran en auge; con una calidad técnica creciente, unas tramas culturalmente cercanas (Tur-Viñes y Rodríguez-Ferrándiz, 2014) y gracias a las nuevas posibilidades de visionado que ofrece la tecnología, su consumo ha crecido notablemente. No obstante, el fenómeno transmediático aplicado a este formato es aún escaso en España; ha llegado más tarde y muestra notables diferencias con las grandes productoras de narrativas transmedia de Estados Unidos y Reino Unido.

Entre las series transmedia, El Ministerio del Tiempo destaca como auténtico fenómeno social y mediático que ha inundado Internet. Si bien en poco tiempo otras series españolas han seguido su estela, éste es un 
producto narrativo, sociocultural y colaborativo diferente a otras ficciones televisivas. El guion de la ficción explota al máximo la transtextualidad especialmente en forma de inter e hiper textualidad. Muy conectado con estos conceptos encontramos que, desde el primer momento, el universo narrativo de la serie que estamos estudiando se expande por diferentes dispositivos y es enriquecido por las contribuciones de la audiencia, que actúa como prosumidor y no solo como mero consumidor.

La presencia de una amplia transtextualidad -en el sentido gennetiano- en el guion, unido a la transmedia storytelling de la ficción, despierta el interés por analizar el mundo narrativo de la serie desde una perspectiva semiótico-comunicacional a fin de avanzar en la investigación semiótica del entorno digital.

Entendemos por semiótica digital la aplicación de los conceptos de la semiótica tradicional al texto digital, sea oral, escrito, visual o audiovisual. El término lo encontramos por primera vez en una tesis de Dreilinger (1998) del Massachusetts Institute of Technology, donde simplemente se nombra como resultado de un motor de búsqueda innovador analizado en esa investigación doctoral. Pero es en la última década cuando la semiótica digital se toma como objeto de numerosas investigaciones científicas, especialmente en el entorno anglosajón, entre las que destacamos las de Bañuelos (2005), Yekta, (2009), O’Halloran (2013, 2015) Monteiro y Moura (2014) o Khanwalkar (2017). Este último autor se refiere a la semiótica digital como el reto de convertir las teorías y los conceptos de maestros como Hjemslev, Barthes, Lotman o Halliday en una cierta forma de realidad material del entorno digital.

Pensamos con O'Halloran (2013) que las tecnologías digitales interactivas, con facilidades para desarrollar marcos conceptuales y almacenar datos multidimensionales en diferentes niveles de descripción, muestran nuevas formas de conducir la investigación semiótica. Esta investigadora y directora-fundadora del Laboratorio de Análisis Multimodal del Instituto Interactivo y de Medios Digitales (IDMI) de la Universidad Nacional de Singapur (NUS) profundiza en las teorías de Lotman y Uspensky (1979: 229) y encuentra en la tecnología digital "la posibilidad de auto-reduplicación de las formaciones de metalenguaje en un número ilimitado de niveles", con la constante introducción de signos nuevos en la esfera de la comunicación. 


\subsection{Intertextualidad y recepción en la era digital}

A pesar de su uso frecuente en el terreno académico, el vocablo intertextualidad no está recogido en el DRAE. La Fundéu-BBVA nos remite al Diccionario del español actual (Seco, Andrés y Ramos, 2011) que lo define como el conjunto de las relaciones que guarda un texto respecto a otro u otros, tanto en el plano del creador como en el del lector. A su vez el Diccionario de términos clave del Centro Virtual Cervantes entiende por intertextualidad la relación que un texto (oral o escrito) mantiene con otros textos (orales o escritos), ya sean contemporáneos o históricos; el conjunto de textos con los que se vincula explícita o implícitamente un texto constituye un tipo especial de contexto, que influye tanto en la producción como en la comprensión del discurso.

El término intertextualidad fue acuñado por Julia Kristeva en 1969. Esta filósofa y teórica del lenguaje recogió las teorías de Bajtín, quien defendía el carácter dialógico que posee todo discurso. Según el filólogo ruso, cada emisor ha sido antes receptor de otros muchos textos; éstos quedan en su memoria y constituyen la base de cualquier texto que posteriormente produzca. Gérard Genette realiza una profunda contribución a la evolución del concepto de intertextualidad. En su obra Palimpsestos, la literatura en segundo grado (1989), lo incluye en el amplio término de Transtextualidad, entendiendo por ello las diversas formas en que un texto se relaciona con otros textos de manera parcial o total; distingue además cinco categorías: Intertextualidad, o relación de co-presencia entre dos o más textos, manifestada en forma de cita, plagio o alusión; Paratextualidad, o relación de un texto con otros -a modo de títulos, ilustraciones, epígrafes, posters, epílogos, etc.- que lo rodean y prolongan; Metatextualidad, o relación de comentario, donde el texto comentado es citado de forma explícita o evocado implícitamente; Architextualidad, o relación abstracta que se establece entre un texto y el género al que pertenece; finalmente Hipertextualidad o transformación y adaptación de un texto en una obra diferente. En este último caso el texto original es llamado hipotexto y el transformado hipertexto (Genette, 1989, 1987; Beristain, 2003).

Hoy día el vocablo hipertexto se ha convertido en un lugar común que designa conceptos confusos y dispares. En ocasiones se reduce al significado de salto entre dos puntos o relación, o se emplea para referirse 
a un modelo conceptual de organización de la información. El teórico de la crítica literaria, George Landow en su obra Hypermedia and Literary Studies (1991) afirma que el hipertexto es una forma distinta de literatura. Posteriormente lo definirá como "texto compuesto de bloques (o imágenes) unido electrónicamente por medio de múltiples caminos, vínculos, enlaces en una textualidad abierta, perpetuamente sin acabar" (Landow, 1995: 15). Es con este enfoque como se emplea en la narrativa audiovisual.

El concepto de intertextualidad -en palabras de Ruprecht (1991)impulsa una rica creatividad y receptividad en el terreno de las ciencias culturales; tal es el caso de la ficción televisiva y cinematográfica, y supone una evolución del modelo narrativo tradicional. El cine recurre a ella como técnica frecuente. Los estudiosos de la cinematografía adoptan la taxonomía de Genette $(1987,1989)$ y la aplican a sus investigaciones (Iampolski, 1998; Grace, 1999; Grant, 2013; Saera, 2013; Boyle y Reburn, 2015), en especial los vocablos intertextualidad e hipertextualidad.

En España el tema encuentra resonancia en la comunidad científica: lo apreciamos en publicaciones recientes sobre aspectos generales de la intertextualidad cinematográfica (Ferrera, 2016; Miranda y Riesco, 2014; Poyato, 2014; Guardia y Hevia, 2012) o sobre estudios concretos de intertextualidad en creaciones y directores singulares (Mínguez, 2013; Quintana, 2014; Escrivá, 2014; Parés, 2014; Tello, 2014).

La noción de intertextualidad está estrechamente vinculada con una figura retórica, la alusión, "donde se sugiere algo que no se dice, pero que es evocado" (Beristain, 2006: 28). La alusión, en sentido amplio y como estrategia de intertextualidad, es un recurso persuasivo frecuente en la narrativa actual. En este punto coincide con los supuestos de Bajtín sobre el emisor que ha sido anteriormente receptor de muchos textos, y las consecuencias derivadas de este hecho. En la producción audiovisual, las alusiones repercuten en los campos asociativos que corresponden tanto al plano del contenido como al de la expresión (Suárez-Noyola, 2013: 162).

Este recurso a la alusión contribuye a destacar el especial protagonismo que el receptor cobra en los discursos audiovisuales y de forma particular en la ficción televisiva. Coincidimos con Torres-Vitolas (2012) en que la recepción de los contenidos mediáticos interesa tanto a la semiótica como a la ciencia de la comunicación; pero además sostenemos que ambas disciplinas se complementan en la investigación sobre la figura del espectador y sus prácticas interpretativas. En el contexto actual 
eminentemente audiovisual el receptor del mensaje va más allá del concepto de lector modelo de Eco (1991); es interactivo y crea lazos sociales en relación con un grupo, con una comunidad interpretativa de la que se siente parte (Jenkins, 1992: 21-23). Por esta razón, el espectador no es solamente un elemento que tiene que ver con índices de audiencia: es introducido incluso en el mismo acto de construcción del texto. Según el concepto de Obra abierta de Eco (1992: 778), todo texto deja una impresión o huella en el receptor, dialoga y necesita una respuesta. Pues bien, también en el texto audiovisual, gracias a las posibilidades transmediales e hipertextuales derivadas del uso de la tecnología, se produce un proceso de semiosis social. En este punto enlazamos con la transmedia storytelling, que se basa en el concepto general de intertextualidad pero que exige un universo narrativo donde se conectan distintas piezas transmediales, y donde cada una de ellas contribuye a la totalidad de forma exclusiva y valiosa.

\subsection{La narrativa transmedia}

Frente a la estructuración mayoritariamente unitaria y lineal del modelo narrativo clásico, las nuevas plataformas de comunicación se configuran como un puzle en el que el discurso ya no resulta un espacio cerrado, sino que se concibe como un campo abierto de acontecimientos que convierten al usuario en el auténtico autor (Alberich, 2005: 62).

Michael Wesch $(2007)^{2}$ intuyó la conmoción de estos procesos cuando afirmó de forma sugerente: "El texto digital es diferente: es más flexible, es móvil, es sobre todo hiper, hipertexto. El hipertexto puede enlazar no sólo información, la Web es enlazar personas, compartiendo, comercializando, colaborando [...] Todos vamos a necesitar repensar algunas cosas". Según Berlanga y Martínez (2010), en efecto, necesitamos repensar ciertas cuestiones; entre ellas, la construcción narrativa.

En este contex to cobra fuerza la narrativa transmedia. Marco Ferrario señala que uno de los efectos del uso de la tecnología en storytelling es la tremenda implicación del lector $\mathrm{y}$, en consecuencia, su capacitación para

2. Michel Wesch es profesor de la Universidad de Kansas, EE.UU. Autor del sitio web Digital Ethnography de su universidad (http://www.michaelwesch.com/) y del video donde publica estas reflexiones: Web 2.0 The Machine is Us. Recuperado el 10 de abril de 2017 del sitio Web de YouTube: http://www.youtube.com/watch? $v=P L-y w l t L j z k$. 
crear historias con gran tensión narrativa (Ferrario, 2015: 188). Afirma este autor que ahora "El potencial de las historias se puede renovar, redescubrir, reactivar, porque el público potencial al que exponerlas es inmenso, más amplio que nunca". A su vez, el impacto emocional de las historias se puede compartir en tiempo real y, sobre todo, se puede medir. Esta nueva narrativa fluye de forma transmediática, entendiendo por transmedia una forma de narrativa en la que las historias se cuentan a través de múltiples plataformas, cada una de ellas aportando algo nuevo y único al universo narrativo que se crea (Jenkins, 2010; Scolari, 2009). Este concepto ha configurado en los últimos años la noción de narrativa transmedia como una disciplina compleja, amplia y novedosa en su aplicación en la industria del entretenimiento y los contenidos digitales (Montero y Berlanga, 2015). La narrativa transmedia busca a las audiencias líquidas que "ya no están donde solían estar en la época del broadcasting: bien quietas frente a la pantalla del televisor" (Scolari, 2013: 5). Los medios clásicos han visto cómo de repente la audiencia tomaba el control (Bernardo, 2011).

Centrándonos en las series de televisión podemos afirmar que son un campo privilegiado para la narración transmedia y constituyen uno de los primeros casos de interacción colectiva en tiempo real con un contenido por parte de comunidades enormes. Las características de su formato mantienen una peculiar tensión entre sus seguidores - dilatada en el tiempo, como la propia serie-, que no consienten perderse ningún capítulo, y que desean compartir y comentar con otros fans del programa.

Se trata de un cambio de hábitos de consumo de medios (Aldea y Vidales, 2011), más marcado entre los jóvenes, con nuevos dispositivos y pantallas: "contenidos fragmentados para audiencias fragmentadas" (González y López, 2011: 37); que piden contenidos más personalizados a sus gustos: sus formatos preferidos son el cine (24\%) y las series (21\%), y en tercer lugar los documentales (11\%) (González y López, 2011).

Según Rodríguez y Ortiz (2014), la web se diría todavía subsidiaria de los contenidos televisivos, y el teléfono móvil, a su vez, de la web: no hay por lo general una estrategia clara para diferenciar los contenidos y promover el nomadismo de los fans entre las plataformas, sino una explotación extensiva e intensiva de los mismos o similares contenidos en todas ellas. Esta cultura colaborativa y las posibilidades de las tecnologías emergentes han dado lugar al fenómeno de las hipermediaciones o "procesos de intercambio, producción y consumo simbólico que se desarrollan en un 
entorno caracterizado por una gran cantidad de sujetos, medios y lenguajes interconectados tecnológicamente de manera reticular entre sí" (Scolari, 2008: 113-114).

Siguiendo a Ferrario (2015), "las series de televisión constituyen uno de los primeros casos de interacción colectiva en tiempo real con un contenido por parte de comunidades enormes"; desarrollan una gigantesca operación de fanfiction espontánea y muy popular en la segunda pantalla, hasta tal punto que hay quien sigue los capítulos a través de lo que cuentan las comunidades en las redes sociales. Todo ello no solo amplía enormemente el tradicional broadcasting, sino que lo orienta en su sucesiva evolución: los autores tienen muy en cuenta todas las interacciones y las reacciones de las comunidades a la hora de decidir el desarrollo sucesivo de las historias. Un ejemplo claro lo encontramos en el universo generado por la serie $E l$ Ministerio del Tiempo.

\section{MATERIALES Y MÉTODO}

\subsection{La serie: caso de éxito}

El Ministerio del Tiempo es una serie televisiva de ficción creada por los hermanos Pablo y Javier Olivares y producida por Onza Partners y Cliffhanger para RTVE. Está protagonizada por Rodolfo Sancho, Aura Garrido, Nacho Fresneda, Cayetana Guillén Cuervo, Hugo Silva, Juan Gea, Francesca Piñón y Jaime Blanch. El título hace referencia a un organismo secreto del gobierno español que data de la época de Isabel la Católica y que recluta agentes de todas las épocas. El objetivo del Ministerio es impedir que nadie cambie la historia española en beneficio propio. La serie relata las misiones que la patrulla protagonista realiza viajando desde el 2015 al pasado, a través de puertas del tiempo.

La serie consiguió emitir una segunda temporada, gracias al apoyo en redes sociales, y la cadena de televisión que la emite ya ha anunciado una tercera temporada, con 13 episodios, igual que la segunda. La primera temporada la forman 8 capítulos y se emitió desde el 24 de febrero al 13 de abril de 2015. Los datos de audiencia señalan que se alcanzó un total de 2.537 .000 de espectadores y un $12,3 \%$ de cuota de pantalla. La segunda temporada consta de 13 episodios y se emitió desde el 15 de febrero al 23 de mayo de 2017 , con un total de 2.291 .000 espectadores y un $11,9 \%$ de 
cuota de pantalla. Los hermanos Olivares también son los creadores de exitosas series recientes: Isabel y Víctor Ros. A pesar de que El Ministerio del Tiempo no es el producto que más audiencia ha conseguido, Javier Olivares -que se siente orgulloso de todas sus series- es a esta última a quien dedica en la entrevista realizada para este trabajo las siguientes palabras: "no he visto un fenómeno igual".

El Ministerio del Tiempo ha sido objeto de estudio para investigadores del campo de las ciencias sociales, cuyos trabajos han visto la luz apenas un año después de comenzar su emisión. Así, se ha analizado como caso de éxito en Rodríguez y Hernández (2015), estudio que se apoya en la medición de las audiencias, tanto la habitual, como la diferida (personas que la ven una vez emitida). También un reciente estudio de CascajosaVirino ahonda en lo que significa que la serie de TVE El Ministerio del Tiempo es "un caso de éxito", y lo argumenta porque se visibiliza a través de las redes sociales y por los datos de audiencia de su visionado en diferido. "El tráfico relacionado con la web generó que el primer capítulo tuviera un cuarto de millón de visionados" (Cascajosa-Virino, 2016: 65).

Desde otra perspectiva más sociológica, Sánchez-Castillo y Galán (2016) se centran en los aspectos de la comunicación transmedia. Por su parte, Rueda y Coronado (2016) y Francescutti (2016) analizan las formas de narrativizar el pasado histórico en las redes sociales, así como los estereotipos presentes en esta narración.

\subsection{Objetivos y metodología}

El objetivo principal que nos hemos propuesto en este estudio es analizar el mundo narrativo de la serie desde una perspectiva semiótico-comunicacional. Con este fin, una vez estudiado el concepto de intertextualidad y su aplicación al audiovisual, emplearemos una metodología inductiva ya propuesta por Rodríguez y otros (2014) con búsqueda y recopilación de toda la variedad de ejemplos de la expansión transmedia del relato televisivo. El análisis semiótico favorece profundizar en los códigos de comunicación, su contexto cultural y su composición simbólica, hechos que repercuten en conductas de consumo del medio.

La perspectiva semiótica analiza las dimensiones del proceso comunicativo bajo el plano de la sintaxis, la semántica y la pragmática. Para definir cada uno de estos niveles seguiremos a Morris (1985): el 
análisis sintáctico se corresponde con los estudios de forma y distribución (p.43). Por su parte, la semántica "se ocupa de la relación de los signos con sus designata (aquello a lo que refieren), y, por ello, con los objetos que pueden denotar o que de hecho denotan" (p. 55). Finalmente, la pragmática "es la ciencia de la relación de los signos con sus intérpretes" (p. 250). De ahí que un análisis pragmático se interese por las circunstancias en que se produce el proceso de comunicación e interpretación de los signos, en un tiempo, un espacio y una cultura determinados, trascendiendo, de esta forma, el propio texto.

Como metodología de apoyo entrevistamos a Javier Olivares -creador y guionista de la serie- sobre las cuestiones que nos interesa analizar. Esta fuente primaria relató los prolegómenos y los detalles de la construcción de la ficción, hecho que nos ayudó a contextualizar los resultados.

\section{SEMIÓTICA DIGITAL EN EL MINISTERIO DEL TIEMPO}

La digitalización creciente de los últimos años ha supuesto importantes cambios en los contenidos comunicativos. Los criterios tradicionales de clasificación de textos y formatos, funciones del lenguaje, características sintácticas, semánticas o pragmáticas, pierden pertinencia y se ven contaminados por el proceso de hibridación que caracteriza a la cultura digital. Pero la semiótica, como sucede con la retórica, ha sabido producir un andamiaje sólido que permite un análisis estructurado y a la vez flexible para su adaptación a los cambios tecnológicos y sociales (De Marchis, 2013).

\subsection{Morfosintaxis digital}

Según Romera Castillo, en toda narración existen dos temporalidades en vinculación muy ligada: la del universo real representado o tiempo del relato y la del universo ficticio del discurso que lo representa (Romera, 1978: 144). Así se producen diferentes velocidades u órdenes (anacronías), numerosas elipsis y condensaciones de tiempos.

En esta serie distinguimos tres secuencias temporales. La primera, que podríamos denominar la intrahistoria de la historia, se refiere al pasado de los protagonistas. La segunda, se articula alrededor del presente, o la historia del relato, centrada en el día a día del Ministerio secreto, es decir, 
el año 2015. La tercera, serían los viajes en el tiempo al pasado al que se opone la acción del presente. Las tres secuencias, desde el punto de vista de su articulación o sintagmática, rompen con la continuidad tradicional. No van encadenadas, van hiperconectadas. Es en el primer capítulo donde conocemos la historia pasada de los protagonistas. Alonso es un soldado de los tercios de Flandes del siglo XVII; Amelia en la Barcelona del siglo XIX es una de las primeras mujeres universitarias de España, y Julián un enfermero madrileño del año 2015. A estas historias con frecuencia se retornará -físicamente- a lo largo de la serie. Pero las acciones y los deseos de los actores estarán ya condicionados por las vivencias de las otras dos secuencias históricas. La organización textual hace que el relato no tenga una estructura interna simple; la arquitectura formal que subyace bajo la narración hipertextual es compleja e implementada por los elementos de ciencia ficción que configuran la trama. Los agentes reclutados pertenecen a diversas épocas y viajan al pasado. A su vez, personajes del pasado traspasan las puertas del Ministerio y aparecen en el siglo XXI. Las diversas tramas están intrincadas. Con todo, el clímax de la acción se produce normalmente en el presente de los personajes. Aquí también se rompe con lo conocido hasta la fecha: escenas retrospectivas o viajes al futuro, pero sin que el personaje viva su presente en esa otra época más o menos lejana.

Las tramas son abiertas y cerradas (con final previsto o no). Hay una intención de los guionistas de mezclar ambas posibilidades con el objetivo de no caer en el concepto de novela-río (historias colectivas). Las tramas de El Ministerio del Tiempo no están estiradas. Esto rompe con la tendencia de la mayoría de las series españolas, que acumulan decenas o incluso cientos de capítulos y resultan excesivamente largas. No obstante, siguiendo el análisis realizado por Romera (2000), apreciamos en cada una el concepto de opera aperta, en el sentido que Eco proporciona a la expresión; esto es, se da libertad a cada receptor de imaginar un desenlace: y es que la ambigüedad de significados se encuentra en todas las obras a lo largo de la historia (Eco, 1992). En el caso analizado se manifiesta de forma directa en la creación de sub-historias (en forma de diario, cómics o programa radiofónico) por parte de la audiencia quien completa o cambia el desenlace primigenio.

Por otro lado, la serie se aleja de los recursos narrativos estándares que suelen ofrecer las series españolas, y -gracias a las posibilidades del 
montaje-se incorporan recursos novedosos como utilizar un bucle temporal y revivir hasta tres veces el mismo día (capítulo 4, Una negociación a tiempo) o presentarnos diversas épocas simultáneamente, gracias al uso de la pantalla partida (capítulo 7, Tiempo de venganza).

$\mathrm{Si}$ analizamos las dramatis personae que ejecutan dichas tramas, nos encontramos en primer lugar -según la nomenclatura de Greimas y Courtés (1979)- con tres actores protagonistas (la patrulla principal que viaja en el tiempo) y otros funcionarios del Ministerio como personajes presentes en cada capítulo y que, según se desarrolle la trama, también van adquiriendo cierto protagonismo. En cuanto a los papeles actanciales que estos actores realizan, no queda claro quiénes son los actantes sujeto/ objeto ni los actantes auxiliar/oponente, pues -según el guionista- los personajes han sido ideados como protagonistas y antagonistas, pero no de una manera monolítica. El mismo personaje puede ser una cosa o la otra según la situación. Todos de entrada comparten una relación de deseo: preservar la historia de España de aquellos que quieren modificarla para su propio beneficio. Pero este deseo inicial irá cambiando en cada personaje complicando las tramas y las relaciones personales.

Junto a los actores principales de la serie, en cada capítulo cobran protagonismo algunos de los personajes históricos de los periodos a los que hay que viajar para una misión concreta: El Empecinado, Lope de Vega, Hitler, Torquemada, Lazarillo de Tormes, Isabel II o García Lorca (primera temporada); y El Cid Campeador, Miguel de Cervantes, Napoleón Bonaparte, Argamasilla, la loca del Raval o Felipe II (segunda temporada). Algunos de los personajes de épocas pasadas viven permanentemente en la presente, como es el caso de Velázquez quien trabaja como retratista en el Ministerio.

Reproducimos una secuencia del guion del capítulo 3 (Cómo se rescribe el tiempo):

INT/DÍA MINISTERIO COMEDOR [2015]

Los integrantes de la patrulla, junto con Ernesto e Irene y otros agentes del Ministerio celebran el cumpleaños de Velázquez.

Angustias entra con una tarta con una vela encendida y la coloca delante de Velázquez.

IRENE 
(Sonríe) ¿Sólo una vela?

ANGUSTIAS

Quien quiera saber cuántos cumple Velázquez, que lo busque en la Wikipedia.

Francescutti (2016) en la comunicación titulada "El sueño de un pasado bajo control: la historia de España según El Ministerio del Tiempo" atribuye al Ministerio el rol de destinador, como fuerza que mueve a los sujetos en pos de sus objetivos. El destinatario -el receptor de las metas o acciones de los sujetos- sería el presente, la España actual representada en el Ministerio. Los coadyuvantes o personajes que ayudan a los sujetos a alcanzar sus objetivos serían los agentes auxiliares del Ministerio: Ambrosio de Espínola, Grande de España; el pintor Velázquez; un abogado experto en derecho medieval; y colaboradores externos: el rabino Abraham Levi, Isabel I. Como antagonistas se podrían identificar, bien personajes singulares (ex-agentes desleales, Torquemada), ideologías (el nazismo) o el destino adverso.

\subsection{Semántica digital}

Al tratar la dimensión semántica de esta ficción no podemos dejar de hablar del concepto mundos posibles ficcionales. Según Doležel (1998), el autor que crea un mundo ficcional literario se inspira en el mundo real de muchas maneras: adaptando sus elementos y categorías macroestructurales; tomando prestados hechos en bruto, temas culturales o rasgos discursivos, anclando o combinando la historia ficcional en un suceso histórico, compartiendo marcos de referencia para crear un escenario ficcional, etc.

En esta serie la realidad aporta un valioso material a la configuración de los mundos narrativos (la historia española es la base de cada capítulo), pero ese material bruto se hiper-transforma sin perder su referencialidad. Así conoceremos cómo el Cid murió unos años antes de lo que la historia oficial transmite; también que Miguel de Cervantes tuvo que viajar al futuro para convencerse de la importancia y trascendencia de su Quijote. Estaríamos ante constantes ucronías o hechos históricos que nunca pasaron, según el término acuñado por el filósofo Renouvier (1857). Esta historia alternativa, subgénero dentro de la narrativa fantástica (Belmonte, 2015: 67) es una de las características de la serie que le ha dado una nota 
de innovación.

Los diferentes escenarios de las misiones conectan con la acepción de cronotopos planteada por Mijaíl Bajtín (1989), y es fundamental para comprende las relaciones espacio-temporales que se encuentran latentes en esta obra. En la serie de ficción El Ministerio del Tiempo se debe tener en cuenta una dimensión más: estar de forma viva en un tiempo pasado, en siglos anteriores, pero no como un narrador intradiegético ni tampoco extradiegético, sino de forma distinta. Vemos cómo en cada relato coexisten distintos cronotopos que se articulan y relacionan en la trama textual y especialmente con los personajes, creando una atmósfera especial y un determinado efecto. Coincidimos con Amelia Álvarez-Méndez quien afirma que el espacio "genera sentimientos y estímulos en el hombre", quien se convierte en el sujeto productor y consumidor del mismo mediante su perspectiva y sus sentidos; así, "con la mirada semántica del espacio", se logra que los lugares narrativos no sean neutros, sino ámbitos asociados e integrados a los personajes y acontecimientos de la historia (ÁlvarezMéndez, 2003).

El eje semántico es pues, la historia española y la aventura alrededor de dicha historia, eso sí, sazonadas con dosis de humor. Abundan los anacronismos, los juegos de palabras, las expresiones irónicas o metafóricas. Así, en el guion del capítulo 2 (Tiempo de gloria) leemos:

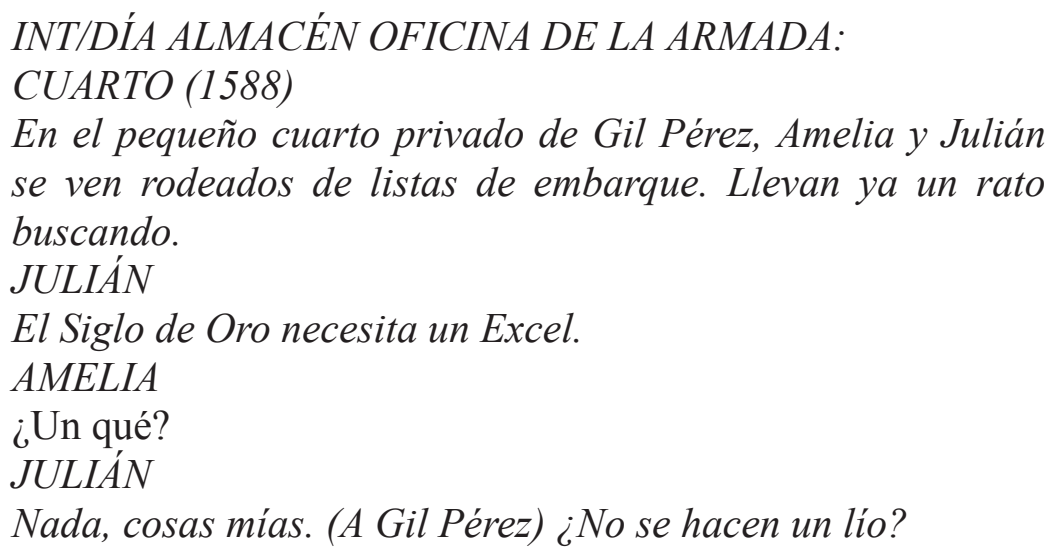

Son continuas las alusiones a realidades de la actualidad social y política (ideología de género, crisis financiera, corrupción política), a programas emblemáticos de la historia televisiva española (por ejemplo, 
Más Allá del doctor Jiménez del Oso) o a los clásicos del cine universal. La teleserie dialoga también con películas de ciencia ficción del siglo XX, que son mencionadas por los protagonistas. También hay reminiscencias del tema principal de la película de ciencia ficción titulada Interstellar (2014). Es así como El Ministerio del Tiempo establece relaciones con otros textos. Conversa, por ejemplo, con series televisivas casi contemporáneas en la pequeña pantalla, como Isabel, con la técnica del crossover -momentos puntuales de una serie en los que aparecen personajes de otra serie más lejanas en el tiempo de emisión-, o como Curro Jiménez (1976-1978). $\mathrm{Y}$ establece audaces relaciones que capturan al espectador: Rodolfo Sancho (Fernando en Isabel y Julián en El Ministerio) es el hijo de Félix Ángel Sancho Gracia, el actor que interpretaba a Curro Jiménez. Los guionistas explotan los conocimientos que el espectador acumula sobre otras ficciones populares y los ponen al servicio de la acción. Y es que el guion es también, como cualquier otro texto, una entidad lingüística, estética y cultural que actúa como estímulo activador de los conocimientos y las experiencias del receptor; en nuestro caso un espectador que puede denominarse competente, según las teorías de Culler (1974), pues opera un proceso de descodificación de los elementos del texto en el que intervienen sus "condicionamientos culturales, el aprendizaje de las relaciones de intertextualidad" (Mendoza, 1998) y su propia experiencia vital y también social por sus relaciones en red.

Cobra interés la relación intertextual con personajes históricos (Buñuel, El Empecinado, Hitler o Torquemada, pongamos por caso) y también con los de ficción como el Lazarillo de Tormes. A su vez, son recurrentes los cameos o rápidas apariciones de personajes famosos de la actualidad representándose a sí mismos en alguna escena. Este recurso sorprende y divierte al espectador y refuerza la conexión entre realidades actuales y temas del pasado.

En la segunda temporada y como novedad, en cada capítulo el planteamiento de la historia se resuelve desde un género cinematográfico distinto. No vemos sólo acción y aventura; hay capítulos que se desarrollan bajo la forma de western, de drama, de terror o suspense, incluso de comedia o vodevil amoroso. Este baile de géneros ha dotado a la serie de mayor dinamismo y ha compuesto un retrato de audiencia muy heterogéneo.

Finalmente destacamos una cuidada y discreta simbología: bajo las apariencias superficiales de los relatos hay signos como elementos 
organizativos abstractos y profundos que generan significados. Es el caso del número 891 de la puerta que conduce a la Residencia de Estudiantes donde la patrulla se encontraría a Lorca, Dalí y Buñuel, y que leído al revés es el 19 de agosto, fecha del asesinato de Lorca.

\subsection{Pragmática digital}

En este apartado tratamos cuestiones como la comunicación misma, el contexto en el que se produce, las normas que lo regulan y los distintos agentes y elementos que participan en ella.

Los puntos de vista desde los que se enfoca la narración son diferentes. No hay un narrador omnisciente. En palabras del guionista hay una información que se comparte con el espectador de diferentes maneras. "Habitualmente, pasamos a acciones en las que unos y otros toman el relevo en cuanto al protagonismo". Y añade que esta información se la ocultan porque quien la sabe es el personaje. "De lo contrario nos haría caer en un exceso de offs que no nos interesan si no son creativos, como los flashbacks".

La forma en que los diferentes agentes participan en la narración nos remite a Talens y otros (1978: 47) cuando afirma que, dentro del nivel pragmático, se integran tanto los elementos referidos a la relación autor/ obra y a la correspondiente obra/lector, como al lugar de inserción de ambos. Efectivamente, autor y, en nuestro caso, público son a la vez productores y productos del discurso. El texto (audiovisual) se presenta como el factor primordial de la comunicación donde el autor y el receptor pierden parte de su entidad. Mutatis mutandis se pueden aplicar al narrador de las tramas de El Ministerio del Tiempo, las mismas funciones que Talens otorgaba al autor de la obra poética (1978: 49). El autor se presenta desprovisto de intencionalidad, una función-lugar con tres características: organización de un mundo como alusión a las relaciones que se establecen entre la historia real y la del texto; trascendencia de lo concreto-individual, que tiene que ver con el cuestionamiento de los contenidos y la manera de tratarlos; y deseo de placer intelectual y/o físico que se refiere a la esteticidad. Aquí entra en juego el receptor a quien, según Carreter, "le corresponde poner en marcha todo el proceso comunicativo" (1987: 168), y quien recrea las escenas según su formación, cultura o su estado anímico.

El contexto de cada personaje contribuye al juego de la ironía y 
genera una comunicación creativa y persuasiva. El hecho de que convivan personajes de distintas épocas (recordemos que los protagonistas provienen cada uno de un siglo; XVII, XIX y XXI) otorga variedad de significado a las palabras, a las acciones y a las intenciones, afectados por los determinados contextos y circunstancias y por el uso de las fórmulas de cortesía de las respectivas culturas. Así la transcripción de una escena del capítulo 8 ( $L a$ leyenda del tiempo) nos dice:

\section{EXT./DÍAJARDINES RESIDENCIA (1924)}

La patrulla está ya en los jardines de la residencia, pero aún no se divisa ésta...

AMELIA

¿No te gusta el Tenorio?

JULIÁN

La primera vez que la vi me gustó. Pero acabé harto de verla tantas veces... La ponían todos los años en la tele la noche de difuntos.

ALONSO

¿La noche de difuntos?

AMELIA

Sí, es que salen espíritus y esas cosas.

ALONSO

Mal asunto hacer chanzas con esos temas.

JULIÁN

Pues ahora es peor, que tenemos Halloween.

AMELIA

Halloween...

JULIÁN

Sí.. Una tradición yanqui. La gente se disfraza de

muertos, de zombis y se va de fiesta.

ALONSO

A los muertos se les debe un respeto. Yo he matado a muchos hombres en batalla, pero luego siempre recé por ellos.

JULIÁN

Mira qué detalle... 
Son frecuentes los momentos en los que el interlocutor no comparte los mismos referentes del hablante, ni se entienden las implicaciones de los mensajes utilizados. Los protagonistas respectivamente sufren un proceso de comunicación truncado, pues, aunque reconocen el significado lingüístico codificado, no son capaces de inferir cuál es el significado que el emisor quiso dar, ni el contenido que quiso transmitir.

\section{SALVADOR}

Bien, como la señorita Folch sabrá, Lope de Vega se enroló en la Armada.

AMELIA

No se sabe con seguridad.

SALVADOR

¡Oh, ya lo creo que se sabe!

IRENE

(A Amelia, sonriendo)

Querida, te olvidas de dónde estás...

SALVADOR

Hemos hablado por skype con nuestro hombre en

Valencia, que es donde vivía, y nos ha confirmado su partida.

JULIÁN

¿Pueden conectarse por skype con el pasado?

ALONSO

¿Qué es un eskaip?

SALVADOR

Luego se lo explica Julián...

Escenas que recogen la llegada del protagonista del siglo XVII a un contexto actual producen un cierto desconcierto en el resto de los actantes, donde los comportamientos no verbales -especialmente la gestualidad- y la ironía toman realce.

Con respecto a los receptores, Olivares destaca "el proceso de comunicación fragmentario basado en las emociones". El componente emocional está presente en este caso de éxito, gracias a las redes sociales. Además, ahora, el que antes era solo espectador -la audiencia pasivapasa a ser prosumidor, porque la multipantalla o los reality games 
(historia afectada por los participantes) han configurado el nuevo perfil del consumidor, logrando también lazos de fidelidad entre el medio y el usuario (Merino, 2013). El constante y extenso flujo de participación, crítica y feedback entre creadores y espectadores es uno de los rasgos distintivos de esta serie.

\begin{tabular}{|c|c|}
\hline \multicolumn{2}{|c|}{ MORFOSINTAXIS } \\
\hline Secuencias temporales & Hiperconectadas \\
\hline Tramas & Abiertas y cerradas \\
\hline Dramatis personae & Protagonistas y antagonistas \\
\hline Mundos ficcionales posibles & Ucronías, cronotopos \\
\hline Eje semántico & Giros, metáforas, ironía \\
\hline Intertextualidad/hipertextualidad & - Personajes históricos/ personajes \\
\hline & \\
\hline ficcionados
\end{tabular}

Tabla 1. Esquema de semiótica digital en El Ministerio del Tiempo

Fuente: Elaboración propia 


\subsection{Expansión transmedia en El Ministerio del Tiempo}

Los sistemas intertextuales transmedia de la teleserie El Ministerio del Tiempo responden a la idea defendida por Scolari, quien considera que las audiencias han cambiado, porque antes se construían en torno a un medio, mientras que ahora se forman en muchos medios y plataformas alrededor de una narrativa. En la serie fluye el transmedia storytelling, un hilo narrativo común para diferentes medios y dispositivos, cada uno de ellos enriquecido por la participación de su propia audiencia (Scolari, 2013).

Un ejemplo claro lo encontramos en el universo generado por la serie analizada donde el alcance de las historias se renueva, se redescubre, se reactiva, porque el público potencial es inmenso, más amplio que nunca. A su vez, el impacto emocional de las historias se puede compartir en tiempo real y, sobre todo, se puede medir. Desde el comienzo de su emisión, en febrero de 2015, ya estaba en marcha el denominado universo transmedia de la teleserie en múltiples plataformas, que se han ido incrementando de manera exponencial.

Es fácil comprobar, pues, que la convergencia entre medios y transmedia permite la participación colaborativa, junto con una cultura de participación creativa, de los usuarios, ahora prosumidores, y fans (Roig, 2010). Tras la emisión del segundo capítulo ya estaba en marcha un colectivo fandom $^{3}$ que genera contenido: post, memes (unidad de mensaje cultural de una mente a otra), fanfic (ficción de fans), etc.

Precisamente, la gestión del contenido generado por las comunidades de fans ha desarrollado departamentos como el de los community managers, que a su vez se dedican a potenciar la figura del prosumidor (Montoya et $a l, 2014)$. Sin embargo, la televisión mantiene la primacía como origen del contenido, mientras que la web es subsidiaria.

Veíamos cómo otra característica de esta nueva narrativa es el cambio de hábitos de consumo de medios por un público que pide contenidos más personalizados a sus gustos: es el caso de los podcast o cómics generados de la historia principal.

3. Término que proviene de la contracción de fanatic kingdom (Reino Fan) y según la versión online del Oxford English Dictionary significa "The world of enthusiasts for some amusement or for some artist". Se suele aplicar especialmente referido a la literatura fantástica o de ciencia ficción, y más en concreto a comunidades virtuales que discuten temas relacionados con su afición. 
Rodríguez y Hernández (2015: 96-97) afirman que la convergencia representa un cambio cultural, puesto que anima a los consumidores no solo a buscar información, sino a expresar y compartir sus ideas, emociones y puntos de vista, lo que lleva a la narrativa transmedia "con el propósito de crear una experiencia de entretenimiento unificada y coordinada". Estos autores hacen suya la definición de televisión social de LorenteCano (2011) explicada como "la creciente convergencia entre la televisión y las redes sociales, mediante la cual los espectadores pueden compartir en todo momento aquellos contenidos televisivos que más les interesan y otorgando un valor añadido a la experiencia audiovisual".

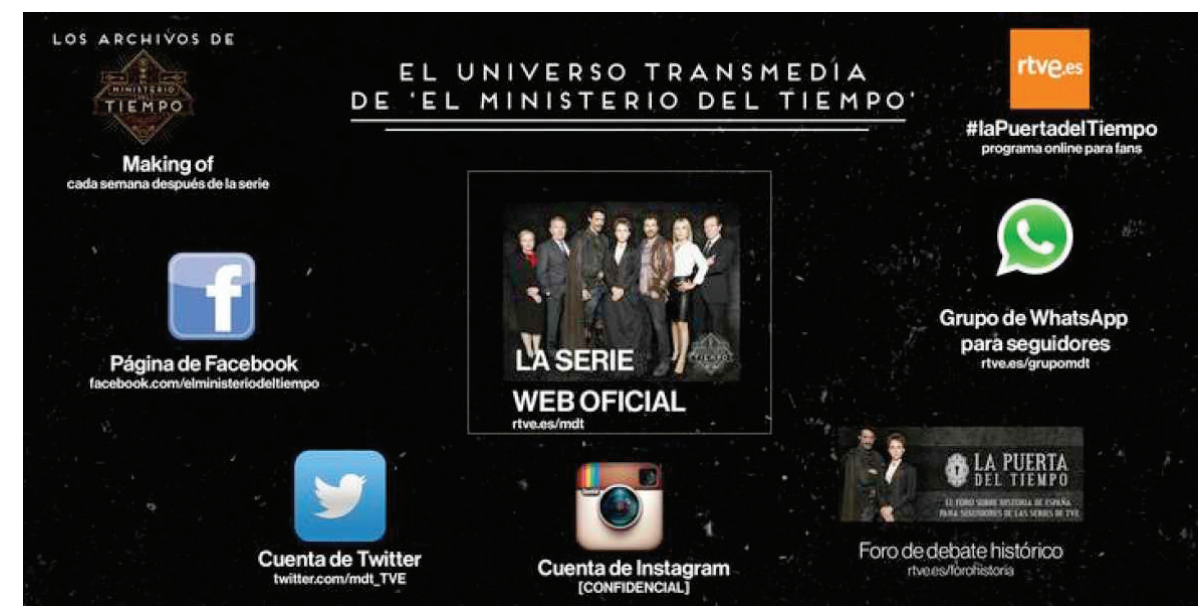

Imagen 1. Infografía del universo transmedia de El Ministerio del Tiempo, según la web de RTVE

Como concreción de la expansión transmedia en El Ministerio del Tiempo distinguimos:

a) La web oficial de la serie, que alcanzó los 292.000 usuarios únicos en una de sus primeras semanas de emisión. Esta web se ha renovado para dar a conocer más de la tercera temporada ( rtve.es $/ m d t)$, con fichas completas de cada personaje y una intranet con contenidos adicionales. Junto a la web se mantiene el mundo transmedia que funciona desde el principio y que se detalla a continuación.

b) Un programa de making of: Los Archivos del Ministerio. 
c) El foro de debate histórico en la web de RTVE.es (5.000 usuarios únicos en distintas semanas elegidas de forma aleatoria), compuesto de audiencia especializada.

d) El grupo de Whatsapp Los becarios del Ministerio.

e) El programa online \#LaPuertadelTiempo.

f) Las cuentas en Facebook, Twiter @Mdt_TVE, Instagram (funcionaba a modo de archivo secreto del Ministerio) a las que recientemente se añadió Telegram. Cabe destacar que los retuits y los trendingtopics se valoran tanto como el antiguo ranking televisivo de la era del broadcasting.

g) El videoblog con el que contará el personaje de Angustias (Francesca Piñón) para explicar lo que sucede a su alrededor, intercalando información de los capítulos y su vida personal.

h) La primera novela El tiempo es el que es, escrita por los guionistas televisivos Anaïs Schaaff y Javier Pascual.

i) Además, se anuncia un evento transmedia para la tercera temporada: el lanzamiento del primer episodio de realidad virtual interactivo, donde los fans podrán visualizar en la web un teaser ${ }^{4}$ que recrea en 2D las imágenes que los transportarán dentro del Ministerio, donde se les hará un examen para decidir si pueden formar parte de una patrulla del tipo.

En la entrevista que hemos realizado a Javier Olivares queda de manifiesto que Twiter ha sido "un canal fundamental por la cantidad y la calidad de comentarios positivos". Olivares analiza el porqué del éxito. En su opinión, se debe a que no se ha tratado al público como mero consumidor, a lo que se añade "que los creadores han podido entrar en contacto directo con el público". También en este caso las redes han funcionado como un nuevo y atractivo canal que las marcas desean utilizar para reactivar su alicaído branding: escuchar, segmentar, hablar, conversar, movilizar, ayudar e involucrar a los posibles clientes para convertirlos en sus usuarios fieles (Campos, 2008).

4. Anglicismo con el que se señala un formato audiovisual breve utilizado como campaña de lanzamiento de un nuevo producto. 


\section{CONCLUSIONES}

El análisis semiótico de la serie El Ministerio del Tiempo nos ha conducido a las siguientes reflexiones.

La semiótica encuentra en el medio digital y audiovisual un importante terreno para avanzar. La continua emergencia de tecnologías provoca el surgimiento de nuevas dimensiones comunicativas: los discursos muestran contenidos flexibles, abiertos e ilimitados que exigen la actualización y redefinición de los modelos anteriores. La semiótica aporta al contexto comunicativo actual sus presupuestos teóricos para profundizar en conceptos como los del autor, la recepción de los contenidos -ahora mediáticos-o la figura del lector-espectador y sus prácticas interpretativas.

El espectador es mucho más que una audiencia pasiva. Es un lectorespectador competente; sabe descodificar los elementos del texto en un proceso de retroalimentación texto/lector o, mejor, ficción televisiva/ prosumidor. Así, el texto audiovisual como entidad lingüística, estética y cultural activa y estimula los conocimientos y las experiencias del receptor. El autor-guionista explota los conocimientos que el espectador acumula sobre otras ficciones o textos como efectos originados por el concepto de obra abierta o de la acción enciclopédica que toda lectura (o recepción de discurso) supone, y los pone al servicio del desarrollo de la trama. A su vez, el receptor aprovecha este bagaje y se transforma en prosumidor.

Las diversas formas de transtextualidad, que como técnica frecuente se emplea a lo largo de cada capítulo de la serie analizada, supone, una evolución del modelo narrativo tradicional de contar historias, y actúa como un recurso persuasivo para el espectador: atrapa su atención y fomenta su creatividad para colaborar en la generación de contenidos. Esta narrativa enriquece la experiencia vivida por el usuario, quien, como audiencia fragmentada y deslocalizada pero interconectada tecnológicamente de manera reticular, ha asumido el control.

Las redes sociales han expandido la experiencia televisiva de la serie al convertirse en un vasto territorio en el que compartir los contenidos, las emociones generadas y comentar en tiempo real los distintos episodios; a su vez realizan la función de indicadores y medidores de audiencia, de picos emocionales y pueden definir estas emociones en relación con las diversas tramas.

El análisis realizado ha permitido entrever cuáles son los valores 
culturales que se desglosan en un discurso, en este caso audiovisual, y cómo los receptores interpretan la transmisión de los mismos; permite por tanto un acercamiento a la realidad social. Efectivamente estamos ante un fenómeno narrativo diferente, mediado por la evolución tecnológica y la cultura colaborativa de la sociedad posmoderna que explota al máximo las diferentes formas de transtextualidad.

La metodología empleada para el análisis de la expansión del mundo narrativo transmedia de la serie desde una perspectiva semiótica de la comunicación digital nos ha servido como pauta que explica el éxito del producto: la retroalimentación entre la existencia de una producción audiovisual vanguardista y de calidad, y el proceso de hipermediación generado. Lo digital, efectivamente enriquece las tramas, las relaciones entre los personajes, los mundos narrativos y los procesos dialógicos con otros textos.

Otro elemento indicador de calidad narrativa es el hecho de que la teleserie sea fiel a la Historia. No en vano, Olivares, su productor, es historiador. Se puede decir que en cada capítulo se ofrecen datos históricos que se completan con las infografías que ofrece la página web de la serie. Las tradicionales funciones de los medios de comunicación -informar, formar y entretener-se reconocen en El Ministerio del Tiempo.

En definitiva, la serie se nos presenta como una de las nuevas formas de construir historias colectivas, en la que se puede hablar de convergencia de medios y transmedia, un fenómeno narrativo, tecnológico y sociocultural al mismo tiempo, como resultado de las posibilidades que ofrece en la actualidad la industria del entretenimiento. A su vez, destaca una original forma de emplear las diversas formas de transtextualidad. Estos parámetros bien pueden ser considerados las claves del éxito de esta ficción.

\section{REFERENCIAS BIBLIOGRÁFICAS}

ALBERICH, J. (2005). "Notas para una estética audiovisual digital”. En Comunicación audiovisual digital. Nuevos medios, nuevos usos, nuevas formas, J. Alberich y A. Roig (coords.), 209-226. Barcelona: UOC. 
ALDEA, P. G. y VIDALES, N. L. (2011). “La generación digital ante un nuevo modelo de televisión: contenidos y soportes preferidos". Anàlisi: quaderns de comunicació i cultura 44, 31-48.

ÁLVAREZ-MÉNDEZ, N. (2003). "Hacia una teoría del signo espacial en la ficción narrativa contemporánea". Signa. Revista de la Asociación Española de Semiótica 12, 548-570 (también en http:// www.cervantesvirtual.com/obra-visor/signa-revista-de-la-asociacion-espanola-de-semiotica--1/html/027e2832-82b2-11df-acc7002185ce6064_47.html) [20/12/2016].

BELMONTE, J. (2015). "Ficciones audiovisuales y políticas postelevisivas de la (des)memoria histórica en la cultura española”. F@ro: revista teórica del Departamento de Ciencias de la Comunicación $1.21,53-71$.

BAJTÍN, M. (1989). "Las formas del tiempo y del cronotopo en la novela. Ensayos de poética histórica". En Teoría y estética de la novela, 237-409. Madrid: Taurus.

BAÑUELOS, J. (2005). "Intercambio cultural digital y nuevos simulacros".Enl@ce,2(3).

BERISTAIN, H. (2003). Diccionario de retórica y poética. México: Porrúa.

(2006). Alusión, Referencialidad, Intertextualidad. México: Universidad Nacional Autónoma de México.

BERLANGA, I. y MARTÍNEZ, E. (2010). "Ciberlenguaje y principios de retórica clásica. Redes sociales: el caso Facebook”. Enl@ ce 7.2, 47-61.

BERNARDO, N. (2011). The producer's guide to transmedia: How to develop, fund, produce and distribute compelling stories across multiple platforms. Lisboa-Londres-Dublín-São Paulo: Beactive Books.

BOYLE, K. y REBURN, J. (2015). "Portrait of a serial killer Intertextuality and gender in the portrait film". Feminist Media Studies 15. 2, 192-207.

CAMPOS, F. (2008): "Las redes sociales trastocan los modelos de los medios de comunicación tradicionales". Revista Latina de Comunicación Social 63, 287-293 (también en http://www.revistalatinacs.org/_2008/23_34_Santiago/Francisco_Campos.html) [20/02/2017]. 
CARRETER, L. (1987). “La literatura como fenómeno comunicativo”. En Pragmática de la comunicación literaria, J.A. Mayoral (ed.), 151170. Madrid: Arco / Libros.

CASCAJOSA-VIRINO, C. (2016). "Buscando al espectador serial desesperadamente: la nueva investigación de audiencias y la serie $E l$ Ministerio del Tiempo". Revista Dígitos 2, 53-70.

CULler, J. (1974). Poética estructuralista. Barcelona: Anagrama.

De MARCHIS, G. (2013). "La retórica y el análisis de la tecnología y de la sociedad actuales. Presentación". Revista ICONO14. Revista científica de Comunicación y Tecnologías emergentes, 11(1), 1-4.

DOLEŽEL, L. (1998). Heterocosmica: Fiction and Possible Worlds. Londres: The Johns Hopkins University Press.

ECO, U. (1991). Lector in fabula. Barcelona: Lumen. (1992). Obra abierta. Barcelona: Planeta.

ESCRIVÁ, R. R. (2014). "El universo Psycho: La ansiedad de la influencia en la obra de Hitchcock". L'Atalante. Revista de estudios cinematográficos 18, 60-70.

FERRARIO, M. (2015). "La era digital transforma la narrativa". Anuario $A C / E$ de cultura digital (Madrid: Asociación de Cultura Española), 187-206 (también en http://www.dosdoce.com/upload/ficheros/noticias/201503/anuario_ace_de_cultura_digital_2015.pdf) [01/03/2017].

FERRERA, J. R. (2016). "En torno al proceso adaptativo de obras literarias al cine". Enunciación 21.2, 226-236.

FRANCESCUTTI, L. (2016). "El sueño de un pasado bajo control: la historia de España según El Ministerio del Tiempo". XII Congreso Español de Sociología (también en http://fes-sociologia.com/elsueno-de-un-pasado-bajo-control-la-historia-de-espana-segun-el/ congress-papers/2133) [20/02/2017]

GENETTE, G. (1987). Seuils. París: Éd. du Seuil.

(1989). Palimpsestos. La literatura en segundo grado. Madrid: Taurus.

GONZÁLEZ, P. y LÓPEZ, N. (2011). "La generación digital ante un nuevo modelo de televisión: contenidos y soportes preferidos". Anàlisi: quaderns de comunicació $i$ cultura 44, $31-48$ (también en http://www.raco.cat/index.php/analisi/article/view/248760) [20/02/2017]. 
GRACE, H. (1999). "Review of Iampolski's, The Memory of Tiresias: Intertextuality and Film". Screening the Past 7, 125-141.

GRANT, C. (2013). "Déjà-Viewing? Videographic Experiments in Intertextual Film Studies. Mediascape". Journal of Cinema and Media Studies (también en http://www.tft.ucla.edu/mediascape/pdfs/Winter2013/DejaViewing.pdf) [01/03/2017].

GREIMAS, A. J., y COURTÉS, J. (1979). Diccionario de semiótica. São Paulo: Cultrix.

GUARDIA, M. y HEVIA, T. (2012). "Mímesis en el paradigma del llamado 'cine contemporáneo' y la narración hipermedia". Revista ICONO14. Revista cientifica de Comunicación y Tecnologías emergentes 4.2, 87-98.

IAMPOLSKI, M. B. (1998). The Memory of Tiresias. Intertextuality and Film. Berkeley: University of California Press.

JENKINS, H. (1992). Textual poachers. Television fans\& participatory culture. New York: Routledge.

(2010). Piratas de textos. Fans, cultura participativa y televisión. Barcelona: Paidós.

KHANWALKAR, S. (2017). "Humanities in the Digital World/Or Digital in the Humanities?". The American Journal of Semiotics.

LANDOW, G. (1991). Hypermedia and Literary Studies. Cambridge: Massachusetts Institute of Technology Press.

(1995). Hipertexto: La convergencia de la teoría crítica contemporánea y la tecnología. Barcelona: Paidós.

LORENTE-CANO, M. (2011). “'Social TV' en España: concepto, desarrollo e implicaciones". Cuadernos de gestión de información 1, 55-64.

LOTMAN, J. y USPENSKI, B. (1979). “Mito, nombre, cultura”. En Semiótica de la cultura, Jurij M. Lotman y Escuela de Tartu (eds.), 111-135. Madrid: Cátedra.

MENDOZA, A. (1998). "Intertextualitat i recepció: el conte tradicional". Articles de Didàctica de la llengua i la literatura 14, 13-32.

MERINO, A. (2013). "El factor emocional en la narrativa transmedia y la televisión social”. Fonseca, Journal of Communication 6.1, 226248.

MÍNGUEZ, N. (ed.) (2013). Ficción y no ficción en los discursos creativos de la cultura española. Madrid: Iberoamericana. 
MIRANDA, I. P. y RIESCO, B. L. (2014). "Historia y cine. El pasado en movimiento". El Futuro del Pasado: revista electrónica de historia $5,25-28$

MONTEIRO, D. y MOURA, A. (2014). "Knowledge Graph and Semantization in Cyberspace: A Study of Contemporary Indexes". Knowledge Organization 41(6).

MONTERO, F. y BERLANGA, I. (2015). "Relaciones y precedente entre animación y narrativa transmedia". En Claves de la comunicación para niños y adolescentes, A. Álvarez-Ruiz y P. Núñez (coords.), 177-240. Madrid: Fragua / Icono 14.

MONTOYA, D.; VÁSQUEZ, M. y SALINAS, H. (2014). "Sistemas intertextuales transmedia". Revista Co-herencia 10, 137-159 (también en: http://www.scielo.org.co/pdf/cohe/v10n18/v10n18a05.pdf) [20/02/2017].

MORRIS, CH. (1985). Fundamentos de la teoría de los signos. Buenos Aires: Paidós.

O'HALLORAN, K.; PODLASOV, A. y TAN, S. (2013). "Multimodal digital semiotics: the interaction of language with other resources". Text \& Talk 33(4-5), 665-690.

O'HALLORAN, K. (2015). "Multimodal digital humanities". En International Handbook of Semiotics, P.P. Trifonas (ed.), 389-415. Netherlands: Springer.

PARÉS, M. (2014). "Intertextualidad en La piel que habito: pintura, escultura y dibujo". Fotocinema. Revista cientifica de cine y fotografia 9, 325-360.

POYATO, P. (2014). "La transducción al cine de la novela". Signa 23, 731-752 (también en http://e-spacio.uned.es/fez/view/ bibliuned:signa-2014-23-7300) [20/02/2017].

QUINTANA, A. (2014). "Las imágenes supervivientes de Quentin Tarantino". L'Atalante. Revista de estudios cinematográficos 18, 36-42.

RODRÍGUEZ-MATEOS, D. y HERNÁNDEZ-PÉREZ, T. (2015). “Televisión social en series de ficción y nuevos roles del documentalista audiovisual: el caso de El Ministerio del Tiempo". Index. comunicación 5.3, 95-120.

RODRÍGUEZ, R.; ORTIZ, F. y SÁEZ, V. (2014). “Contenidos transmedia de las teleseries españolas: clasificación, análisis y panorama en 2013". Communication \& Society 27.4, 73-94. 
ROIG, A. (2010). "Nuevos media y formas de producción participativas". En Exploraciones Creativas: Prácticas artísticas y culturales de los nuevos medios, G. San Cornelio (ed.), 11-163. Barcelona: UOC Press.

ROMERA CASTILLO, J. (1978). "Teoría y técnica del análisis narrativo". En Elementos para una semiótica del texto artístico. Poesía, narrativa, teatro, cine, J. Talens et al. (eds.), 113-156. Madrid: Cátedra. (2000). "Análisis semiótico de un cuento de Clarín: El viejo y la niña". Biblioteca Virtual Miguel de Cervantes (en http://www.cervantesvirtual.com/nd/ark:/59851/bmcw37s2) [20/01/2017].

RUEDA LAFFOND, J. C. y CORONADO RUIZ, C. (2016). "Historical science fiction: from television memory to transmedia memory in El Ministerio del Tiempo". Journal of Spanish Cultural Studies 17.1, 87-101.

RUPRECHT, H. G. (1991). “The reconstructio of intertextuality”. En Intertextuality, H. Plett (ed.), 60-77. Berlin: De Gruyter.

SAERA, Y. (2013). "Intertextuality in Kurosawa's Film Adaptation of Dostoevsky's The Idiot". CLCWeb: Comparative Literature and Culture 15. 4, 1-10 (también en: http://dx.doi.org/10.7771/14814374.2032) [11/02/2017].

SÁNCHEZ-CASTILLO, S. y GALÁN, E. (2016). "Transmedia narrative and cognitive perception of TVE ${ }^{e e}$ drama series El Ministerio del Tiempo". Revista Latina de Comunicación Social 71, 508-526 (también en http://www.revistalatinacs.org/071/paper/1107/27en. html) [10/02/2017].

SCOLARI, C. (2008). "Hacia la hipertelevisión. Los primeros síntomas de una nueva configuración del dispositivo televisivo". Diálogos de la Comunicación 77, 1-9.

(2009). "Narrativa transmediática, estrategias crossmedia e hipertelevisión”. En Lostología. Estrategias para entrar y salir de la isla, A. Piscitelli, C. A. Scolari y C. Maguregui (eds.), 69-100. Buenos Aires: Cinema.

(2013). Narrativas transmedia. Cuando todos los medios cuentan. Barcelona: Deusto Ediciones.

SECO, M.; ANDRÉS, O. y RAMOS, G. (2011). Diccionario Español Actual. Madrid: Aguilar.

SUÁREZ-NOYOLA, G. (2013). "Intertextualidad en el cine de Tim Bur- 
ton". La Colmena 80, 161-162.

TALENS, J.; ROMERA, J.; TORDERA, A. y HERNÁNDEZ, V. (1978). Elementos para una semiótica del texto artístico. Poesía, narrativa, teatro, cine. Madrid: Cátedra.

TELLO, L. (2014). "Transtextualidad y metaficción en el falso documental: el discurso autorreferencial en The Unmaking of". Communication \& Society 27.4, 113-129.

TORRES-VITOLAS, M.A. (2012). "Formas de recepción de la televisión: ¿nuevos lectores o nuevas lecturas?". 10th World Congress of the International Association for Semiotic Studies (en http://ruc.udc. es/dspace/handle/2183/13484) [20/03/2017].

TUR-VIÑES, V. y RODRÍGUEZ, R. (2014). "Transmedialidad, Series de Ficción y Redes Sociales: El caso de Pulseras Rojas en el Grupo Oficial de Facebook (Antena 3. España)". Cuadernos. Info 34, 115131.

YEKTA, R. (2009). "Digital semiotics in ESP/EAP materials development: The study of the effects of DVD options for developing textindependent thinking and Reading". International Journal of Language Studies 3(4).

Recibido el 1 de marzo de 2017.

Aceptado el 16 de abril de 2017. 